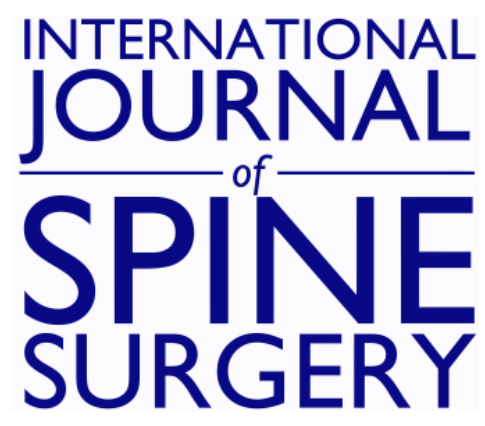

\title{
Ligamentum Flavum Cyst With Acute Onset Motor Deficit: A Literature Review and Case Series
}

KALYAN KUMAR VARMA KALIDINDI, MOHD RAFIQ BHAT, MAYANK GUPTA, ABHISHEK MANNEM and HARVINDER SINGH CHHABRA

Int J Spine Surg 2020, 14 (4) 544-551

doi: https://doi.org/10.14444/7072

http://ijssurgery.com/content/14/4/544

This information is current as of April 26, 2023.

Email Alerts Receive free email-alerts when new articles cite this article. Sign up at:

http://ijssurgery.com/alerts

The International Journal of Spine Surgery

2397 Waterbury Circle, Suite 1,

Aurora, IL 60504, Phone: +1-630-375-1432 


\title{
Ligamentum Flavum Cyst With Acute Onset Motor Deficit: A Literature Review and Case Series
}

\author{
KALYAN KUMAR VARMA KALIDINDI, MS, DNB, MOHD RAFIQ BHAT, MS, MAYANK GUPTA, MS, \\ DNB, ABHISHEK MANNEM, MS, DNB, HARVINDER SINGH CHHABRA, MS \\ Indian Spinal Injuries Centre, Vasant Kunj, New Delhi, India
}

\begin{abstract}
Background: Ligamentum flavum cysts have been rarely described in the literature and are one of the rare causes of neural compression and canal stenosis. Very few cases of their association with neurologic deficits are reported to date, and association with acute onset weakness is even rarer.

Clinical Presentation: We report our experience with 3 cases of ligamentum flavum cyst that presented with acute onset weakness and also present a comprehensive literature review on lumbar ligamentum flavum cysts reported to date. All 3 patients had symptoms of severe neurogenic claudication and presented to us with acute onset of motor weakness in lower limbs. Ligamentum flavum cyst was located in the midline in 2 cases and laterally in 1 case. We performed excision of the cyst and decompression with fusion in 2 cases and decompression alone in 1 case. All 3 cases had significant improvement in their neurologic status postoperatively. Histopathological examination confirmed ligamentum flavum cyst in all 3 cases. We performed a PUBMED and EMBASE database search using the MeSH (Medical Subject Headings) terms "ligamentum flavum" and "cysts" for articles published to April 2019. We could identify 7 studies describing 20 cases of lumbar ligamentum flavum cysts with motor weakness in the literature. Only 1 case had been described with an acute onset of weakness.

Conclusions: Ligamentum flavum cysts should remain in the differential diagnosis of a patient who has symptoms of lumbar canal stenosis and presents with acute onset of neurological deficits. Such patients have a good improvement with surgery.
\end{abstract}

\section{Lumbar Spine}

Keywords: lumbar spine, ligamentum flavum cyst, acute onset neurologic deficit, cyst excision and confirmed on histopathology, literature review and case series

\section{BACKGROUND}

The most commonly reported cystic lesions in the spine are synovial cysts (lined by a true synovial lining) or ganglion cysts. ${ }^{1,2}$ Ligamentum flavum cysts were first reported by Moiel et $\mathrm{al}^{3}$ in 1967. Ligamentum flavum cysts are unique lesions without a synovial lining (cf synovial cysts) and are associated with a pseudocystic degeneration of the ligamentum flavum. ${ }^{4}$ They are a rare cause of canal stenosis and compression of neural structures. The origin of ligamentum flavum cysts was proposed to be secondary to microtrauma due to hypermobility at the spinal segment and associated degenerative changes. $^{2,5}$ They are found mostly in the most mobile and degenerative segments of the spine, with almost more than half of ligamentum flavum cysts found in the lumbar spine at the L4-L5 level and the remainder at L5-S1 and L3-L4. ${ }^{6}$ Most often, they are diagnosed during surgery, but if looked at closely, they can be diagnosed preoperatively by magnetic resonance imaging (MRI). ${ }^{7}$ The symptoms produced by ligamentum flavum cysts depend on their location, size, and rate of growth. ${ }^{6}$ Only a few cases of their association with neurologic deficits have been documented in the literature to date, and acute onset of weakness is even rarer. Various treatment modalities, including conservative methods such as analgesics, braces, physiotherapy, steroid injections, and even repeated aspiration of cysts, have been attempted for symptomatic ligamentum flavum cysts with less favorable results. ${ }^{6}$ Surgical resection of the cyst along with the affected ligamentum flavum removal is advised when they cause neurological symptoms or intractable pain. ${ }^{8,9}$ We present our experience with 3 cases of ligamentum flavum cysts that developed an acute onset of neurologic deficit. 


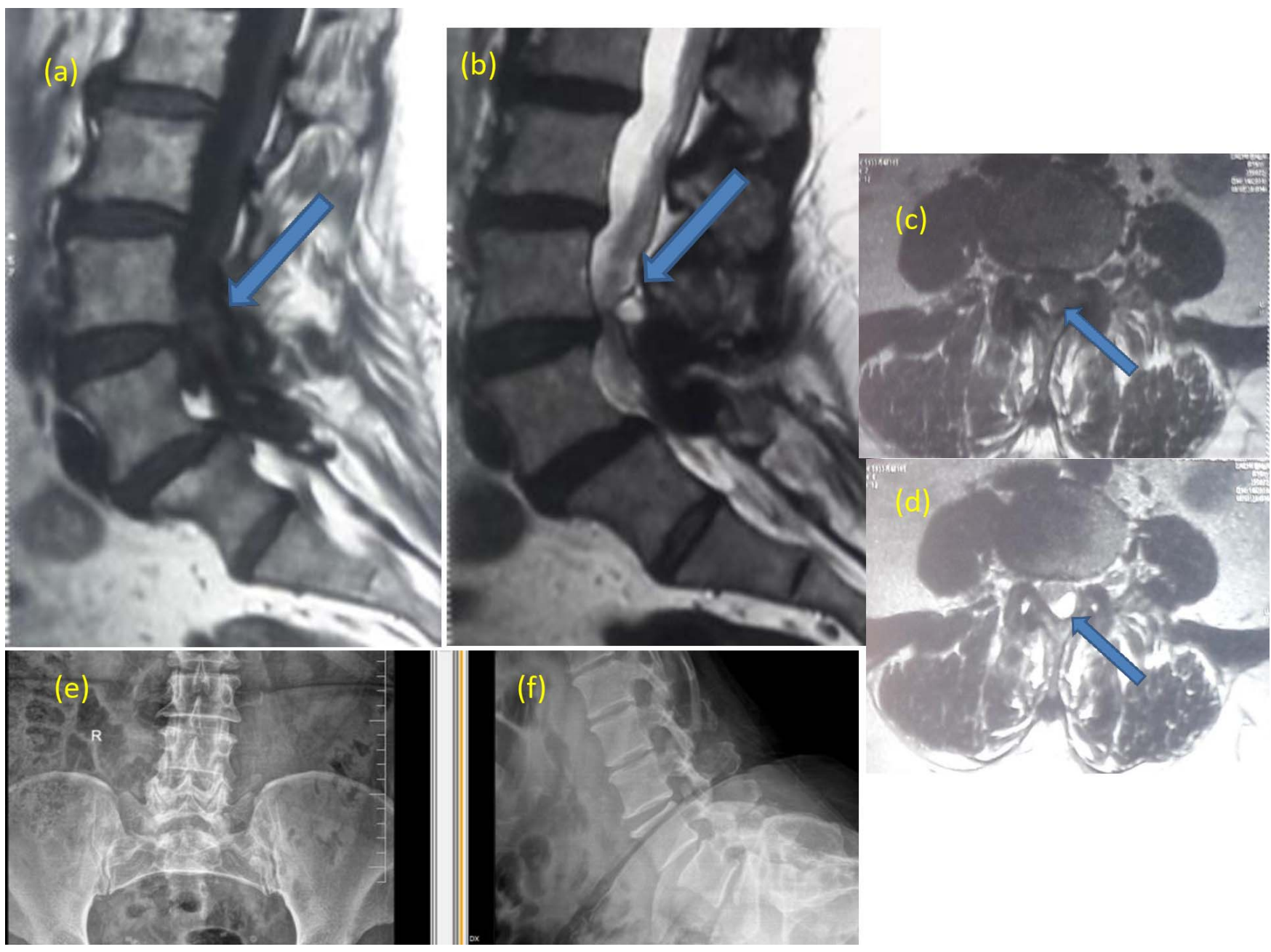

Figure 1. Case 1. (a, b) Sagittal T1- and T2-weighted magnetic resonance images of the patient showing a lesion hypointense on T1 and hyperintense on T2 within the posterior spinal canal at the L4-L5 level compressing the thecal sac (marked with blue arrow). (c, d) Axial T1- and T2-weighted MRI image at the L4-L5 level of the patient showing a lesion with hypointense signal (similar to cerebrospinal fluid signal) on T1 imaging and hyperintense signal on T2 imaging in the midline and slightly to the left (marked with blue arrow). (e, f) Anteroposterior and lateral x-rays of the lumbosacral spine of the patient showing degenerative changes at the L4-L5 and L5$\mathrm{S} 1$ levels. Grade 1 spondylolisthesis at L5-S1 can be appreciated on the lateral view.

\section{CLINICAL PRESENTATION}

\section{Case 1}

A 55-year-old female presented to us with symptoms of neurogenic claudication for the past 1 month and acute onset of weakness in both legs for the past 10 days. The claudication distance was less than $50 \mathrm{~m}$. The left-sided symptoms were predominant. Neurologic examination revealed the weakness of the ankle dorsiflexors (grade $3 / 5$ on the right side, grade $0 / 5$ on the left side) and extensors of the great toe (grade $3 / 5$ on the right side, grade $0 /$ 5 on the left side) and plantar flexors of the ankle (grade 4/5 on both sides). X-rays and MRI of the patient revealed a grade 1 spondylolisthesis at L5S1 with severe lumbar canal stenosis at the L4-L5 and L5-S1 levels (Figure 1). There was a cystic lesion within the ligamentum flavum at the L4-L5 level in the midline and slightly to the left. We performed posterior instrumentation at the L4-S1 level, transforaminal lumbar interbody fusion at the L5-S1 level, and lamino-foraminotomy with cyst excision at the L4-L5 level (Figure 2). There were dense adhesions between the ligamentum flavum and the thecal sac that were released, and the cyst was removed. Histopathological examination of excised specimen was consistent with a ligamentum flavum cyst (Figure 2). Postoperatively, there was a significant improvement in pain symptoms. The weakness also improved completely, and she was asymptomatic at 1 year follow-up. 


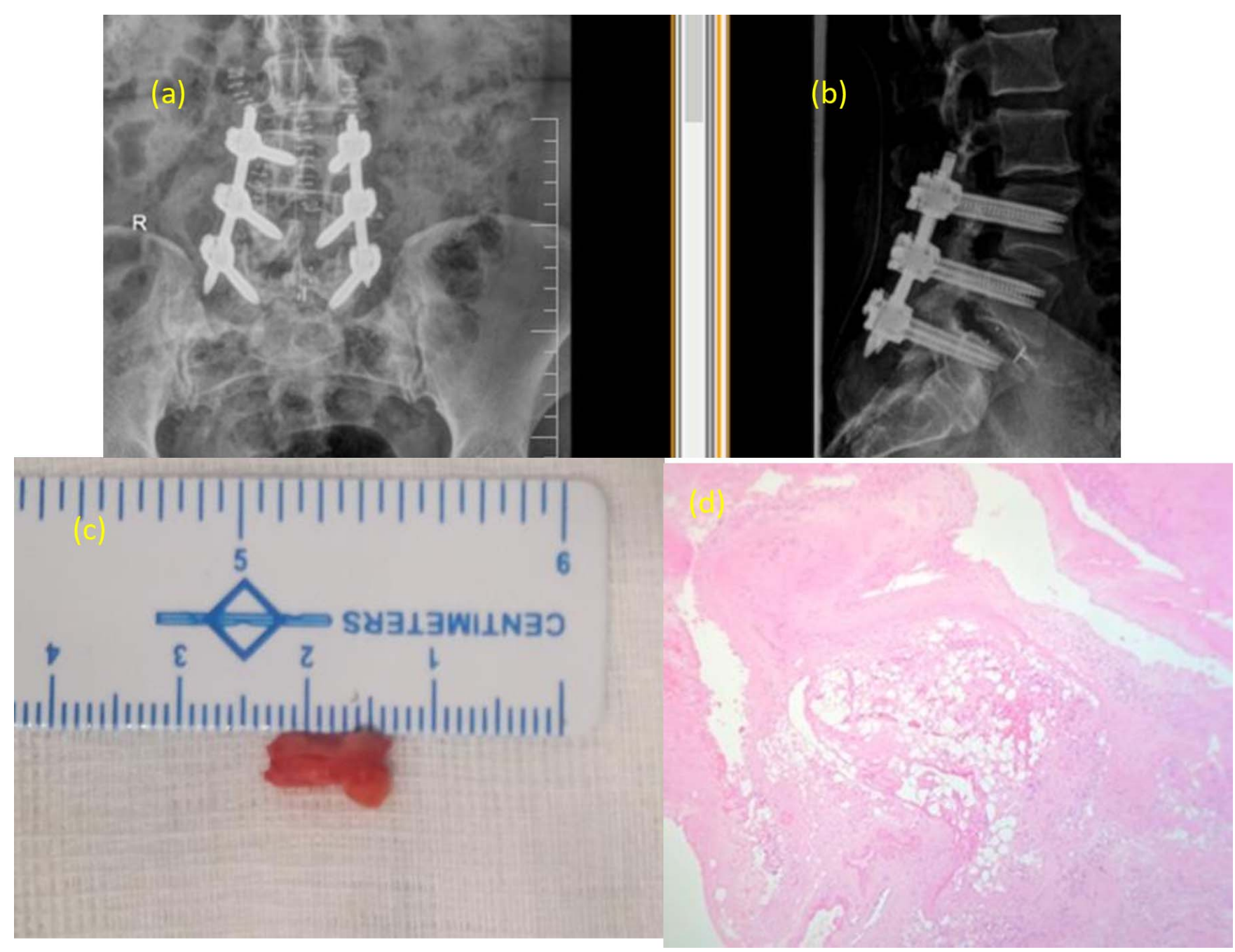

Figure 2. Case 1. (a, b) Postoperative anteroposterior and lateral x-rays of the patient showing posterior instrumentation from L4 to S1 and transforaminal lumbar interbody fusion at the L5-S1 level. (c) Image showing the excised ligamentum flavum cyst measuring about $1 \mathrm{~cm}$ in length. (d) Histopathological slide of the cyst shows a cystic lesion lined by a fibro-connective tissue with mild chronic inflammatory infiltrate and fibroblast proliferation. Few proliferating blood vessels are seen. There is no lining epithelium, consistent with a ligamentum flavum cyst.

\section{Case 2}

A 69-year-old male presented to our emergency department with an acute onset progressive weakness of both legs for the past week. He had a history of low back pain with neurogenic claudication in both legs for 5 years. The patient had a claudication distance of fewer than a hundred meters. He had a history of trivial fall at home 1 month previously.

Clinical examination revealed the weakness of bilateral extensors of the great toe $(1 / 5$ on the right side, $3 / 5$ on the left side) and right ankle plantar flexors $(3 / 5$ on the right side). X-rays of the lumbosacral spine suggested degenerative changes, and MRI of the patient suggested canal stenosis at the L4-L5 level with grade 1 spondylolisthesis at the L4-L5 level. We missed the ligamentum flavum cyst on MRI (Figure 3). We performed a posterior decompression by laminectomy of L4 along with posterolateral fusion from L4 to S1 (Figure 4). We found a cystic lesion in the midline compressing the thecal sac (Figure 4). Retrospectively, on reviewing the MRI films, a ligamentum flavum cyst was noted in the midline at the L4-L5 level (Figure 3). Histopathological examination confirmed the diagnosis of ligamentum flavum cyst. He had good improvement in pain symptoms and foot weakness and returned to work at 6-month follow-up. He was doing well at 2-year follow-up.

\section{Case 3}

A 70-year-old male with a chronic history of back pain with bilateral buttock and leg pain for 3 years presented with aggravated symptoms for the past 1 month. Clinical examination revealed weakness of 


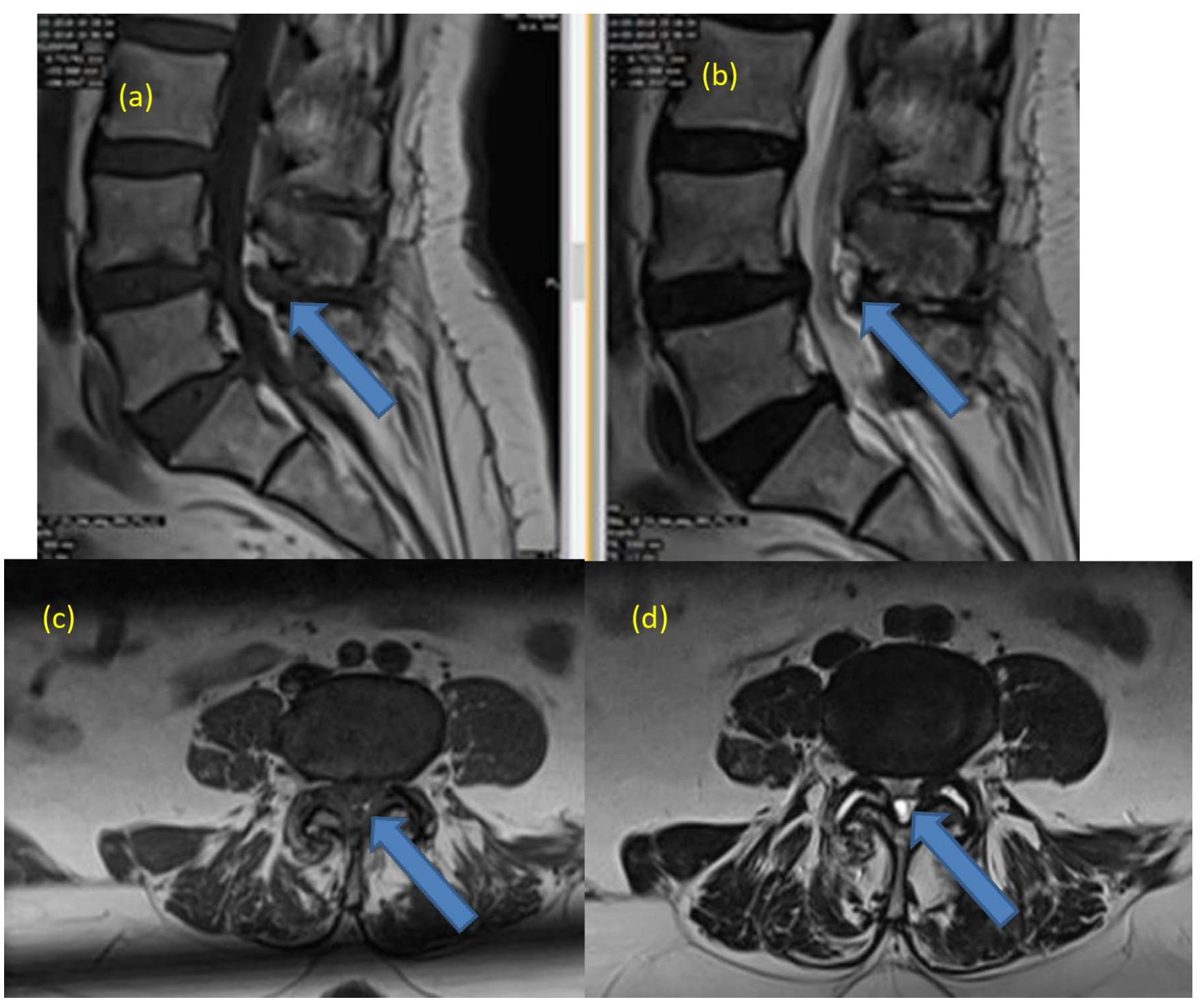

Figure 3. Case 2. (a, b) Sagittal T1- and T2-weighted magnetic resonance images of the patient showing a lesion hyperintense on T2 and hypointense on T1 at the L4-L5 level within the posterior spinal canal compressing the thecal sac (marked with blue arrow). (c, d) Axial T1- and T2-weighted magnetic resonance images at the L4-L5 level of the patient showing a lesion with hypointense signal (similar to cerebrospinal fluid signal) on T1 and hyperintense on T2 in the midline (marked with blue arrow) compressing the thecal sac.

the ankle dorsiflexors (grade $1 / 5$ on both sides), of the extensors of the great toe (grade $1 / 5$ on both sides), and of the hip abductors (grade $2 / 5$ on both sides).

MRI of the lumbar spine showed severe lumbar canal stenosis causing neural compression at the L3-L4 and L4-L5 levels. A 2-level posterior decompression by laminectomy from L3 to L5 was done, and a cystic mass within ligamentum flavum was noted on the left side. The cyst was completely excised, and histopathological examination of the excised specimen was consistent with a ligamentum flavum cyst. The weakness improved gradually, and the patient was able to walk unsupported at 6- month follow-up. He was doing well at 2-year follow-up.

\section{DISCUSSION}

We performed a PUBMED and EMBASE database search using the MeSH (Medical Subject Headings) terms "ligamentum flavum" and "cysts" for articles published to April 2019. All articles in the English-language literature describing ligamentum flavum cysts were included regardless of study design. All relevant and related articles were studied. Full-text articles were retrieved, and the neurological status of all the patients in the 

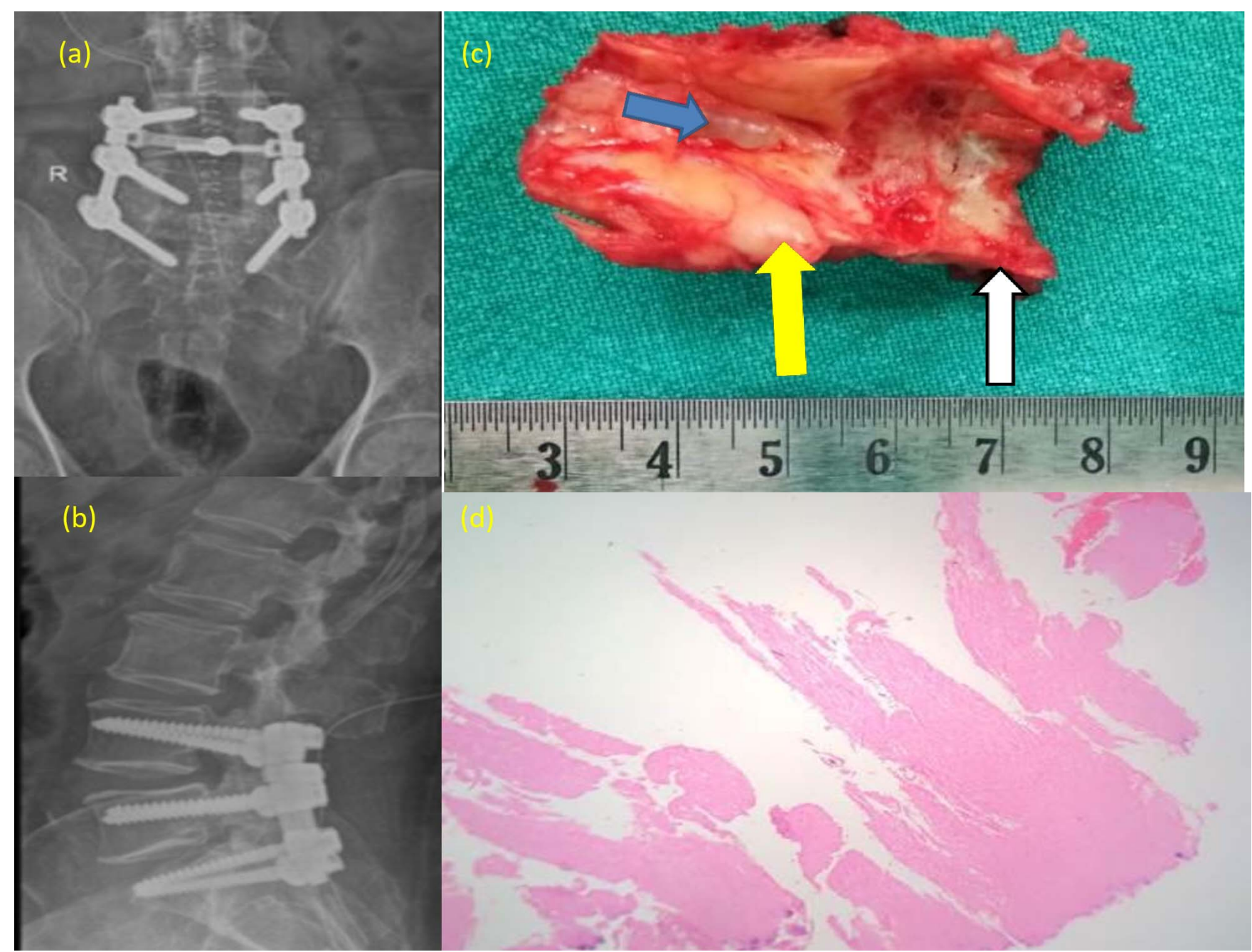

Figure 4. Case 2. (a, b) Postoperative anteroposterior and lateral x-rays of the patient showing posterior instrumentation from L4 to $S 1$ with accurately placed screws. (c) Specimen showing the excised laminae (marked with white arrow) along with ligamentum flavum (marked with yellow arrow) en masse. The ligamentum flavum cyst (marked with blue arrow) can be clearly seen on the inner surface of the ligamentum flavum. (d) Histopathological slide of the cyst showing fibro-elastic tissue with chondroid metaplasia and areas of calcification. There is no lining epithelium, consistent with a ligamentum flavum cyst.

literature with ligamentum flavum cysts was noted wherever available.

We could identify 26 articles on ligamentum flavum cysts in the lumbar spine after excluding irrelevant articles. Seventy-seven cases of ligamentum flavum cysts in the lumbar spine have been reported to date (Table). Seven studies describing 20 cases of lumbar ligamentum flavum cysts have been reported to have a motor weakness (Table). However, only 1 case among them has been reported to have an acute onset of motor weakness. Our series included 3 patients with acute onset motor weakness and biopsy-proven ligamentum flavum cysts. All the patients had good improvement in neurological status after surgical decompression and cyst excision.
Juxtafacetal cyst is a common term used in the literature for any cyst arising from the posterior elements of the spinal canal. ${ }^{1,2}$ However, identifying the origin of the cyst and differentiating different types of cysts can help in individualizing the management strategies. Whereas a synovial cyst has communication with the facet joint and is lined by a synovial lining, ganglion cysts are pseudocysts lined by a fibrous wall. ${ }^{2,4}$ A ligamentum flavum cyst is an entity less described in the literature. Flavum cysts are unique in having no communication with the facet joint, arising within the ligamentum flavum, and having no epithelial lining. ${ }^{19,22,30}$ They can grow into the spinal canal and compress the neural structures and produce symptoms of neurogenic claudication or radiculopathy or neurologic deficit. $^{13,17,19,20,22,23,30-32}$ 
Table. Chronological list (from the most recent to the earliest) of relevant studies on ligamentum flavum cysts in the lumbar spine to April 2019. The studies that reported motor deficits due to ligamentum flavum cysts are in bold.

\begin{tabular}{|c|c|c|c|}
\hline Study & Year & $\begin{array}{l}\text { No. of } \\
\text { Patients }\end{array}$ & $\begin{array}{c}\text { No. of Patients } \\
\text { With Motor Deficit }\end{array}$ \\
\hline Kim et $\mathrm{al}^{10}$ & 2019 & 1 & 0 \\
\hline Shah et $\mathrm{al}^{7}$ & 2018 & 1 & 0 \\
\hline Nizamani $^{11}$ & 2017 & 1 & 0 \\
\hline Wang $^{12}$ & 2017 & 1 & Not available \\
\hline Börekci $^{13}$ & 2017 & 1 & 1 \\
\hline Ghent et al ${ }^{6}$ & 2014 & 1 & 0 \\
\hline Seo et $\mathrm{al}^{14}$ & 2014 & 1 & 0 \\
\hline Massimo et $\mathrm{al}^{15}$ & 2012 & 1 & 0 \\
\hline Wu et $\mathrm{al}^{16}$ & 2011 & 1 & 0 \\
\hline Chan et $\mathrm{al}^{17}$ & 2010 & 3 & 2 \\
\hline Taha et $\mathrm{al}^{18}$ & 2010 & 1 & 0 \\
\hline Ayberk et $\mathrm{al}^{19}$ & 2008 & 2 & 0 \\
\hline Gazzeri et al $^{20}$ & 2007 & 1 & 1 \\
\hline Asamoto et $\mathrm{al}^{21}$ & 2005 & 1 & 0 \\
\hline DiMaio et $\mathrm{al}^{22}$ & 2005 & 4 & 1 \\
\hline Wildi et al $^{23}$ & 2004 & 33 & 13 \\
\hline Cakir et $\mathrm{al}^{24}$ & 2004 & 1 & 0 \\
\hline Terada et $\mathrm{al}^{25}$ & 2001 & 1 & 0 \\
\hline Barlocher et $\mathrm{al}^{26}$ & 2000 & 1 & 0 \\
\hline Mahallati et $\mathrm{a}^{27}$ & 1999 & 1 & 0 \\
\hline Bloch et $\mathrm{al}^{28}$ & 1997 & 6 & Not available \\
\hline McBride $^{29}$ & 1994 & 1 & 0 \\
\hline Baker and Hanson ${ }^{30}$ & 1994 & 1 & 0 \\
\hline Vernet et $\mathbf{a l}^{31}$ & 1991 & 6 & 1 \\
\hline Abdullah et al $^{32}$ & 1984 & 4 & 1 \\
\hline Haase $^{33}$ & 1972 & 1 & 0 \\
\hline
\end{tabular}

Segmental instability has been described as a major role in the pathogenesis of ligamentum flavum cysts. ${ }^{23,34,35}$ The hypermobility at the lower lumbar segments associated with repeated microtrauma due to instability results in the weakening of elastic fibers within the flavum that consequently undergo cystic degeneration. We found a segmental instability with grade 1 spondylolisthesis in 1 of the 3 cases at the same level and in 1 case at the adjacent level. We are of the opinion that the instability may contribute to the formation of ligamentum flavum cysts. Hence, stabilization of the segment becomes equally important to cyst resection and decompression to prevent a recurrence in those cases that are associated with instability. The occurrence in elderly patients with degenerative changes in the spine suggests that the aging process may have also contributed to the formation of ligamentum flavum cysts.

Wildi et $\mathrm{al}^{23}$ reported that the ligamentum flavum cysts exclusively occurred in the medial part of the ligamentum flavum and caused thickening of the ligament. However, DiMaio et $\mathrm{al}^{22}$ reported that most of the cysts were located laterally within the spinal canal due to the thin ligament and less resistance at the posterior recesses laterally. We found that the cysts were located in the medial part of flavum in 2 of our cases and laterally in 1 case.

Seo et $\mathrm{al}^{14}$ reported that a majority of the patients with ligamentum flavum cysts present with radicular pain ( $97 \%$ of the cases) or neurologic symptoms and may mimic symptoms of intervertebral disc herniation. However, the acute onset of neurologic deficits has been very rarely documented. Rupture of vessels within the cyst with subsequent hemorrhage and neural compression has been proposed by Gazzeri et $\mathrm{al}^{20}$ as the reason for acute onset of motor weakness in their case. They could appreciate a subacute hematoma on MRI imaging done 2 days after the onset of symptoms. However, chronic hematoma into the cyst has been noted in other studies as well. ${ }^{27,36,37}$ In our series, all the cases presented late after an acute onset of neurologic deficit, and MRI did not reveal a hematoma. We assume that the late presentation may have led to the negative finding on MRI in our study.

The thickened ligamentum flavum containing the cyst has variable signals on T1-weighted images and a high-intensity signal on T2-weighted images on MRI. Nizamani ${ }^{11}$ mentioned that ligamentum flavum cysts may be difficult to diagnose on MRI, as the usual MRI images are focused on the intervertebral discs. They can be easily identified on MRI if looked at carefully. However, the presence of blood, gas, air, or proteinaceous content can alter the signal intensity. ${ }^{38}$ In our study, all 3 cases had a hyperintense signal on T2-weighted MRI imaging and a hypointense signal on T1weighted MRI imaging.

There are no high-quality studies on the management of lumbar juxta facetal cysts. ${ }^{6}$ However, differentiating synovial cysts from ligamentum flavum cysts is important, as synovial cysts often adhere to dura, difficult to resect, and commonly require facet joint exploration. ${ }^{11}$ Percutaneous aspiration of the cysts has been associated with a high recurrence and failure. Spontaneous regression of cysts has also been documented in synovial cysts. The management of symptomatic ganglion cysts is usually surgical, although spontaneous regression has been documented similar to synovial cysts. Conservative management has not been successful, and percutaneous steroid injections or aspiration of cysts have not shown good long-term results in the management of ligamentum flavum cysts. ${ }^{14}$ In view of severe symptoms and acute onset of neurologic deficit, surgical treatment was advised in all our 
cases. All 3 patients responded well to surgical decompression with cyst excision and had good improvement in the neurological status postoperatively. Dural adhesions may cause difficulty in the removal of cysts en masse and cause surgical morbidity. In our study, we found dural adhesions and difficulty removing the cyst in 1 case. However, there were no complications, and the cyst could be removed completely.

Our study suggests that ligamentum flavum cysts have the potential to cause acute neurological deficits and respond well to surgery. However, due to the rarity of occurrence of the entity and no highquality evidence, the role of conservative treatment in patients who present with ligamentum flavum cysts cannot be commented on.

\section{CONCLUSIONS}

Ligamentum flavum cysts should remain in the differential diagnosis of a patient who presents with symptoms of lumbar canal stenosis, especially those with an acute onset of neurologic deficit. Careful preoperative reading of the MRI images may aid in the diagnosis. Such patients have good outcomes with surgery.

\section{ACKNOWLEDGMENTS}

The authors would like to thank the concerned patients for allowing the details to be shared.

\section{REFERENCES}

1. Rhoton AL, Kao CC, Uihlein A. Extradural ganglion cyst. In: Vinken PJ, Bruyn GW, eds. Handbook of Clinical Neurology. Amsterdam: North-Holland; 1976:605-609.

2. Kao CC, Winkler SS, Turner JH. Synovial cyst of spinal facet: case report. J Neurosurg. 1974;41(3):372-376. DOI: 10. 3171/jns.1974.41.3.0372

3. Moiel RH, Ehni G, Anderson MS. Nodule of the ligamentum flavum as a cause of nerve root compression. Case report. J Neurosurg. 1967;27(5):456. DOI: 10.3171/jns.1967.27. 5.0456

4. Chebib I, Chang CY, Schwab JH, Kerr DA, Deshpande V, Nielsen GP Histopathology of synovial cysts of the spine. Histopathology. 2018;72(6):923-929. doi:10.1111/his.13465.

5. Sabo RA, Tracy PT, Weinger JM. A series of 60 juxtafacet cysts: clinical presentation, the role of spinal instability, and treatment. J Neurosurg. 1996;85(4):560-565

6. Ghent F, Davidson T, Mobbs RJ. Haemorrhagic lumbar juxtafacet cyst with ligamentum flavum involvement. Case Rep Orthop. 2014; 2014:126067. http://dx.doi.org/10.1155/2014/ 126067

7. Shah K, Segui D, Gonzalez-Arias S. Midline ligamentum flavum cyst of lumbar spine. World Neurosurg. 2017;110:284 287. doi:10.1016/j.wneu.2017.11.075.

8. Christophis P, Asamoto S, Kuchelmeister K, Schachenmayr W. Juxta facet cysts a misleading name for cystic formations of mobile spine (CYFMOS). Eur Spine $J$. 2007;16(9):1499-1505.

9. Banning CS, Thorell WE, Leibrock LG. Patient outcome after resection of lumbar juxtafacet cysts. Spine. 2001;26(8):969-972.

10. Kim HS, Singh R, Adsul NM, Oh SW, Noh JH, Kim PY, Park JH, Park CH, Jang IT, Symptomatic Tuberculous Ligamentum Flavum Cyst Treated by Full Endoscopic Resection: A Review with Technical Notes, World Neurosurgery. 2019;122:112-115 doi: https://doi.org/10.1016/j.wneu. 2018.10.141

11. Nizamani WM. Ligamentum flavum cyst: an uncommon but recognizable and surgically correctable category of juxtafacet cyst. Radiol Case Rep. 2018;13(1):302-304. doi:10.1016/j. radcr.2017.09.009.

12. Wang SC, Wang FF.Lumbar spinal canal stenosis complicated with lumbar ligamentum flavum cyst: a case report. Zhongguo Gu Shang. 2017 May 25;30(5):479-480. doi: 10.3969/j.issn.1003-0034.2017.05.017. [Article in Chinese]

13. Börekci A, Kuru Bektaşoğlu P, Gürer B, Çelikoğlu E. Acute bilateral foot drop as a presenting symptom of hemorrhagic synovial cyst of the lumbar spine. World Neurosurg. 2017; 108:999.e7-999.e9.. doi:10.1016/j.wneu.2017.09.098.

14. Seo D-H, Park H-R, Oh J-S, Doh J-W. Ligamentum flavum cyst of lumbar spine: a case report and literature review. Korean J Spine. 2014;11(1):18-21. http://dx.doi.org/11.14245/ kjs.2014.11.1.18.

15. Massimo M, Vincenzo P, Filippo M P, Stefano F, Carlo D R, Antonino R. Symptomatic ganglion cyst of ligamentum flavum as a late complication of lumbar fixation. Neurologia $\mathrm{i}$ Neurochirurgia Polska 2012; 46, 1: 82-86 doi: 10.5114/ninp. 2012.27344

16. Hao WU;Tian-bao LUO;Wrede Karsten;Feng-zeng JIAN. Recurrent hemorrhage of ligamentum flavum cyst: case report. Chinese Medical Journal.2011;124(24):4361-4363, doi: 10.3760/cma.j.issn.0366-6999.2011.24.042

17. Chan AP-H, Wong TC, Sieh K-M, Leung SS-M, Cheung $\mathrm{K}-\mathrm{Y}$, Fung K-Y. Rare ligamentum flavum cyst causing incapacitating lumbar spinal stenosis: experience with 3 Chinese patients. J Orthop Surg Res. 2010;5:81. doi:10.1186/1749-799X$5-81$

18. Taha H, Bareksei Y, Albanna W,Schirmer M. Ligamentum flavum cyst in the lumbar spine: a case report and review of the literature. J Orthopaed Traumatol. 2010; 11(2):117-122 doi 10.1007/s10195-010-0094-y

19. Ayberk G, Ozveren F, Gok B, et al. Lumbar synovial cysts: experience with nine cases. Neurol Med Chir. 2008;48(7):298-303.

20. Gazzeri R, Canova A, Fiore C, Galarza M, Neroni M, Giordano M. Acute hemorrhagic cyst of the ligamentum flavum. J Spinal Disord Tech. 2007;20(7):536-538.

21. Asamoto S, Jimbo H, Fukui Y, et al. Cyst of the ligamentum flavum - case report. Neurol Med Chir (Tokyo) 2005;45(12):653-6.

22. DiMaio S, Marmor E, Albrecht S, Mohr G. Ligamentum flavum cysts causing incapacitating lumbar spinal stenosis. Can J Neurol Sci. 2005;32(2):237-242. 
23. Wildi LM, Kurrer MO, Benini A, Weishaupt D, Michel BA, Brühlmann P. Pseudocystic degeneration of the lumbar ligamentum flavum: a little known entity. J Spinal Disord Tech. 2004;17(5):395-400.

24. Cakir, E., Kuzeyli, K., Usul, H., Peksoylu, B., Yazar, U., Reis, A., \& Karaarslan, G. . Ligamentum flavum cyst. Journal of Clinical Neuroscience. 2004;11(1), 67-69.doi:10.1016/j.jocn. 2003.02.008

25. Terada H, Yokoyama Y, Kamata N, Hozumi T, Kondo T. Cyst of the ligamentum flavum. Neuroradiology.2001; 43(1):49-51

26. Barlocher CB, Seiler RW. Vertebral erosion and a ligamentum flavum cyst. Case illustration. J Neurosurg.2000; 93(2 Suppl):335

27. Mahallati H, Wallace K, Hunter M, et al. MR imaging of a hemorrhagic and granulomatous cyst of the ligamentum flavum with pathologic correlation. Am J Neuroradiol. 1999;20(6):1166-1168.

28. Bloch J, Hawelski S, Benini A. Cyst of the ligamentum flavum of the lumbar spine: description of 6 cases. Schweiz Med Wochenschr.1997; 26;127(17):728-732

29. McBride DJ. Ligamentum flavum and apophyseal cysts as an unusual cause of root compression. Br J Clin Pract.1994; 48:52-53

30. Baker JK, Hanson GW. Cyst of the ligamentum flavum. Spine.1994; 19(9):1092-1094

31. Vernet O, Fankhauser H, Schnyder P, Déruaz JP. Cyst of the ligamentum flavum: report of six cases. Neurosurgery. 1991;29(2):277-283.

32. Abdullah AF, Chambers RW, Daut DP. Lumbar nerve root compression by synovial cysts of the ligamentum flavum: report of four cases. J Neurosurg. 1984;60(3):617-620. doi: 10. 3171/jns.1984.60.3.0617.

33. Haase J. Extradural cyst of the ligamentum flavum L4: a case. Acta Orthop Scand.1972; 43(1):32-38

34. Howington JU, Connolly ES, Voorhies RM. Intraspinal synovial cysts: 10-year experience at the Ochsner Clinic. $J$. Neurosurg. 1999;91(suppl 2):193-199.

35. Onofrio BM, Mih AD. Synovial cysts of the spine. Neurosurgery. 1988;22(4):642-647. https://doi.org/10.1227/ 00006123-198804000-00004

36. Sweasey TA, Coester HC, Rawal H, et al. Ligamentum flavum hematoma. Report of two cases. $J$ Neurosurg. 1992;76(3):534-537.

37. Mizuno $J$, Nakagawa $H$, Inoue $T$, et al. Ligamentum flavum hematoma in the lumbar spine. Neurol Med Chir. 2005;45(4):212-215.

38. Cho SM, Rhee WT, Choi SJ, Eom DW. Lumbar intraspinal extradural ganglion cysts. J Korean Neurosurg Soc. 2009;46(1):56-59.

Disclosures and COI: The first 2 authors contributed equally in the management of patient, performing the literature search, and preparing the manuscript. The authors received no funding for this study and report no conflicts of interest.

Corresponding Author: Kalyan Kumar Varma Kalidindi, MS, DNB, Indian Spinal Injuries Center, Vasant Kunj, New Delhi, India, 110070. Phone:+91-9597732908; Email: kalyanvarmambbs@ gmail.com.

Published 28 August 2020

This manuscript is generously published free of charge by ISASS, the International Society for the Advancement of Spine Surgery. Copyright (c) 2020 ISASS. To see more or order reprints or permissions, see http://ijssurgery.com. 